\title{
Designing for Movement in Public Life with Itinerant Probes
}

Daniela K. Rosner

Human Centered Design

\& Engineering

University of Washington

Seattle, WA 98195 USA

dkrosner@uw.edu

\section{Margaret E. Morris}

Intel Corporation

Hillsboro, OR 97214

margaret.morris@intel.com

\section{Ariel Duncan}

Human Centered Design

\& Engineering

University of Washington

Seattle, WA 98195 USA

hello@theyeswoman.com

\section{Sarah E. Fox}

Human Centered Design

\& Engineering

University of Washington

Seattle, WA 98195 USA

sefox@uw.edu

\section{Kathi R. Kitner}

Intel Corporation

Hillsboro, OR 97214

kathi.r.kitner@intel.com

\section{Ankur Agrawal}

Human Centered Design

\& Engineering

University of Washington

Seattle, WA 98195 USA

ankurag@uw.edu

Permission to make digital or hard copies of all or part of this work for personal or classroom use is granted without fee provided that copies are not made or distributed for profit or commercial advantage and that copies bear this notice and the full citation on the first page. Copyrights for components of this work owned by others than the author(s) must be honored. Abstracting with credit is permitted. To copy otherwise, or republish, to post on servers or to redistribute to lists, requires prior specific permission and/or a fee. Request permissions from Permissions@acm.org.

DIS 2016, June 04 - 08, 2016, Brisbane, QLD, Australia Copyright is held by the owner/author(s). Publication rights licensed to ACM.

ACM 978-1-4503-4031-1/16/06 \$15.00

DOI: http://dx.doi.org/10.1145/2901790.2901913

\begin{abstract}
This pictorial illustrates how objects can illuminate people's experience of public space, an approach we call itinerant probes. Itinerant probes are not individualized, mediated artifacts, but instead dynamic events that enliven people's personal and collective memories. Building on the probes literature and recent ecological perspectives, we describe three probes related to lighting that we investigated at three public sites. Our explorations with these probes highlight the intimate histories associated with public spaces.
\end{abstract}

\section{Authors Keywords}

Design probes, social inquiry, public space, lighting.

\section{ACM Classification Keywords}

K.4.0 Computers in Society: general.

\section{Introduction}

A design project often unfolds unpredictably. It may begin with a concrete engineering challenge, but end in a proposal for policy changes. The current project also shifted in focus, expanding from a concern for safety and lighting on public stairwells to a broader concern for people's relationship to public space. So doing it transitioned from questions of what might be to what is. In this pictorial, we describe this journey and its resultant process of design, a method we call itinerant probes. 


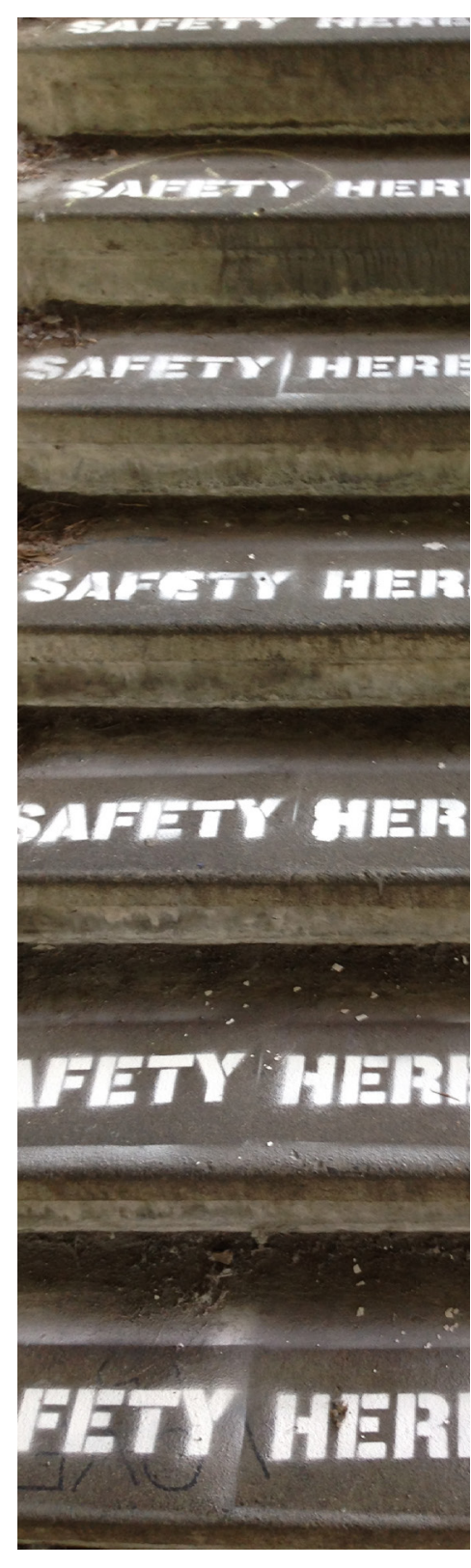

\section{Probes and Itineraries}

Since their introduction in the 1993 Presence project [3, p.22], probes have exercised what design scholars Bill Gaver, Tony Dunne and their colleagues call "a strategy of pursuing experimental design in a responsive way." Through surprising elicitations, probes use ambiguity and provocation as a resource for conversation and collaborative design with interlocutors. In three retirement communities, Gaver and Dunne's design team used packages of materials, from postcards to photo albums, to engage with groups of older adults. The packages posed questions to their interlocutors such as 'What use are politicians?' and 'What is your favourite device?' With these questions their design team aimed to reverse the promise of improving social life through technology, a promise "that tries so hard to be rational" ([3], p.7). Instead, they sought a means of supporting the idiosyncrasies of everyday life, from chatting to creative expression ([3], p.7).

Probes have since inspired a broad range of work across the fields of $\mathrm{HCI}$ and interaction design, from design products to social research insights (e.g., $[1,8]$. But in this exploration of probes in public life, we find new tensions between intervention and inquiry. It is at this intersection we wish to explore design research methods - the meeting of a design-based tradition we began with and the questions of social life we encountered along the way. In so doing, we find probes invite a different set of sensibilities than a mixing of activist and empiricist aims might suggest. Rather than connect opposing goals, our work marries the material techniques of design with the conceptual work of social science, particularly strategies of tracing material histories. We call these methods itinerant probes.

Our development of itinerant probes builds on ecological perspectives in studies of material culture, anthropology and science and technology studies. Such approaches consider the discursive and material arrangements that make certain object relations possible [2]. Anthropologist Tim Ingold [4, p.91] for example stresses the woven, processional form of material production: "at once itinerant, improvisatory and rhythmic." Examining this temporal character in craft objects, archeologist Rosemary Joyce [5] introduces the notion of object itineraries, the spatial and temporary traces "where objects come to rest or are active, the routes through which things circulate, and the means by which they are moved" [5]. A particular point of intervention occupies no higher moral ground than any other; instead traces of the object situation continually change through time and use. Put in terms of design, itinerant probes are temporary interventions in everyday life that conjure salient memories and enliven material relations. As we see in the examples that follow, our probes become objects with itineraries, historicized traces of human experience that surface the fragility of things $[5,7]$.

\section{Where Our Work Began}

Taking place over the course of several months in the spring of 2015, the project began as a shared investigation by researchers of both academic and industrial settings interested in examining how city dwellers move through public space. With a focus on issues of safety, lighting, and engagement, we sought to create a research agenda that was both responsive to our sites of study and highly collaborative. The group consisted of six researchers, half had expertise in design and the other focused on fieldwork. We organized the collaboration around two weekly handoffs. The first involved sharing research findings with the design team through a web blog. The design team then built probes based on the findings and delivered them back to the research team. The research team disseminated these probes, collected insights based on their use, and communicated these findings to the design team - starting our iterative cycle once more. 


\section{Seattle Sites}

We chose three walkways with regular traffic that differed

along several dimensions. The "Wall of Death" is an underpass with stairs leading up to campus and major bus routes. It is part of a bike trail that feels decidedly unwelcoming at night. Pedestrians, particularly women, rush through this area.

A popular and well travelled stairwell, the Rainier Training Grounds connects two affluent Seattle neighborhoods. There we met climbing enthusiasts whose backpacks were filled with rocks or kitty litter, simulating the weight they would be carrying on their next Rainier climb. Many leave piles of sticks at the top of the stairs to count their laps up and down the stairs.

Freeway Park offers a shortcut between a business district and a residential neighborhood. During the day, people told us the park felt "interesting," but at night, said it felt "creepy" due to its multiple pathways dotted with blind spots. The park's walls obscured lines of sight and created voluminous shadows.
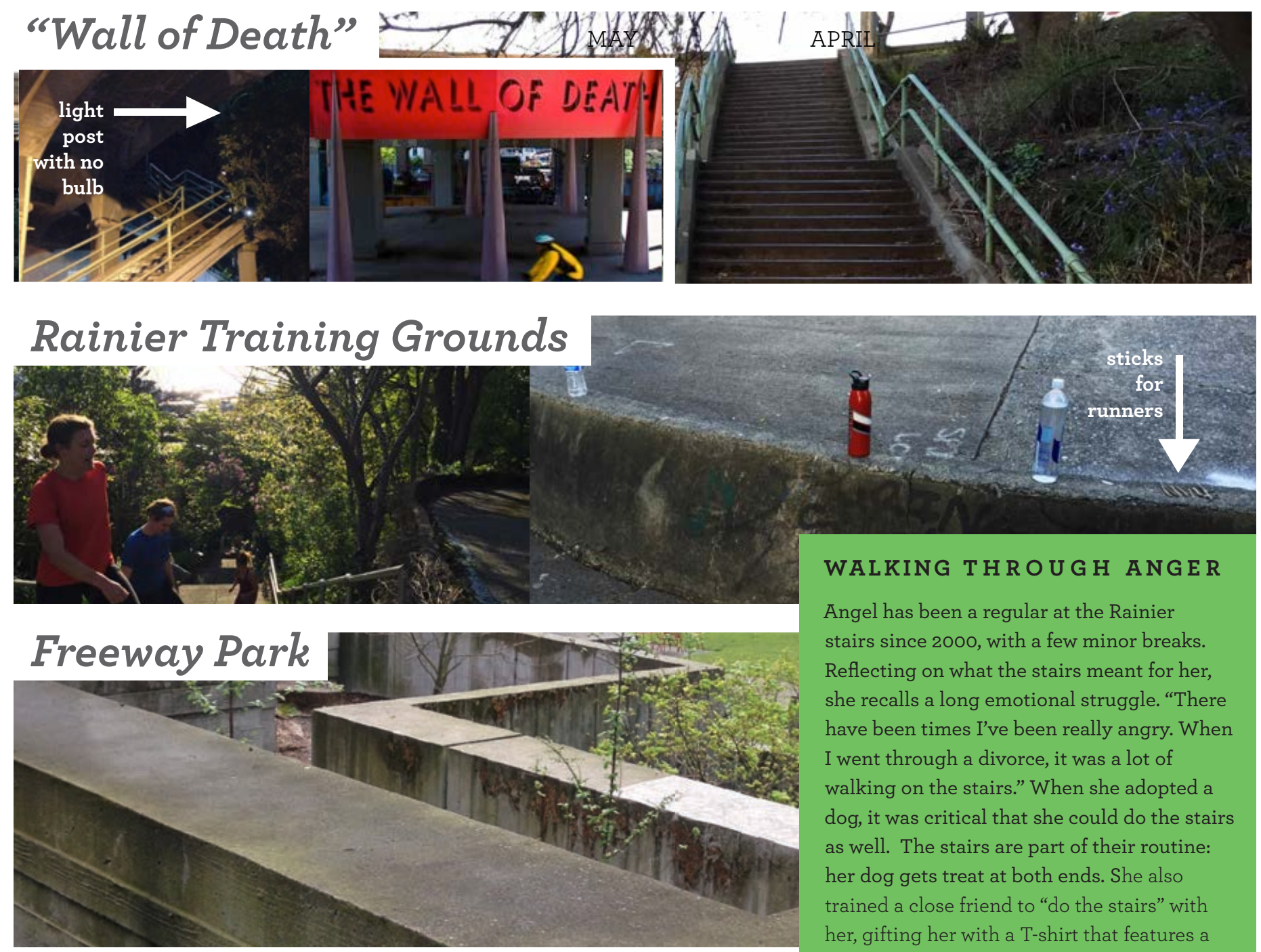

WALKING THROUGH ANGER

Angel has been a regular at the Rainier stairs since 2000 , with a few minor breaks. Reflecting on what the stairs meant for her, she recalls a long emotional struggle. "There have been times I've been really angry. When I went through a divorce, it was a lot of walking on the stairs." When she adopted a dog, it was critical that she could do the stairs as well. The stairs are part of their routine: her dog gets treat at both ends. She also trained a close friend to "do the stairs" with her, gifting her with a T-shirt that features a drawing of stairs and the word "STAIRAPY". 


\section{Timeline Development of Itinerant Probes}

To explore light as an aid for navigating dark public space, we created probes people could attach to a location or leave for someone else. People held some close \& avoided others: clutching light sticks but drawing back from iridescent Play-Dough.

APRIL

To examine the potential of light as a means of navigating public spaces at night, we explored probes that could be attached to the space, left behind by the participants and visible

to the next people on the stairs. But we found that a sudden triggering of lights in the environment could "light up" passersby in ways that made them feel more vulnerable.

MAY

We next created fluorescent pigment in condiment bottles, and invited participants to draw or write on the stairs. Some used the bottles to talk with the light and shared narrative responses with friends and neighbors present. Others left spiritual messages about light with no one recipient in mind.

JUNE

Our final probe pushed further with text. We created stencils with fill-in the-blank messages that people could complete with chalk available on the stairs. The messages included: "Safety here means [blank]" and "If these stairs went away [blank]." Through these probes, we discovered a strong sense of ownership over certain spaces. People expressed idiosyncratic imagination without us present. Others reacted negatively to the stencils and went so far as washing it off.

\section{Where Light Belongs}

Fluorescent lights \& glow-in-the-dark Play-Dough
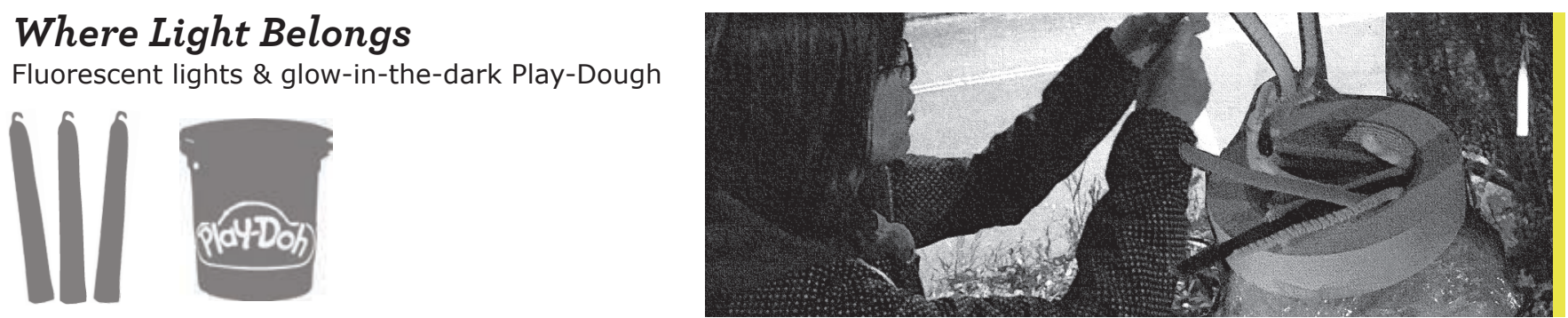

Where Messages Flow

Fluorescent paint in squeeze bottles
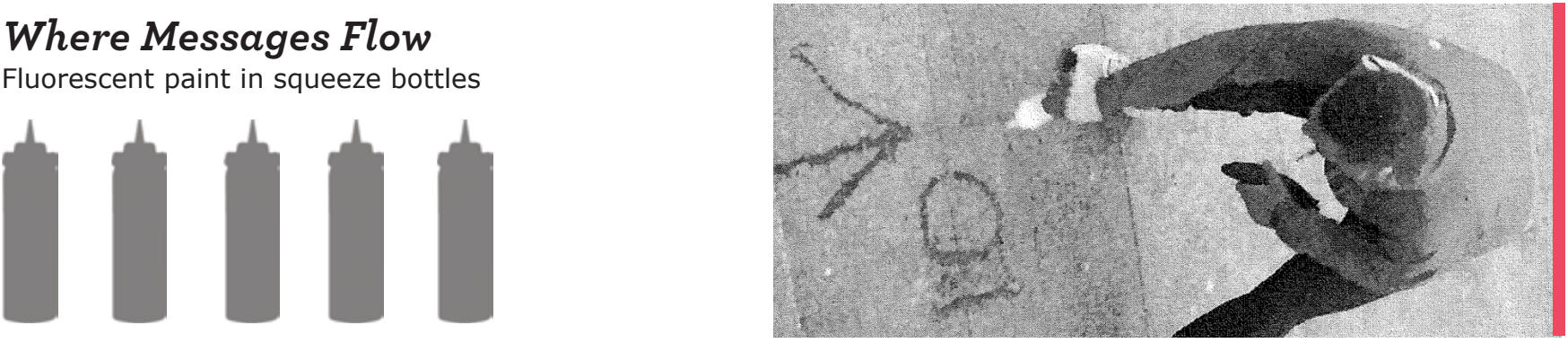

Where Stairs Txt

Fluorescent chalk with fill-in-the-blank messages
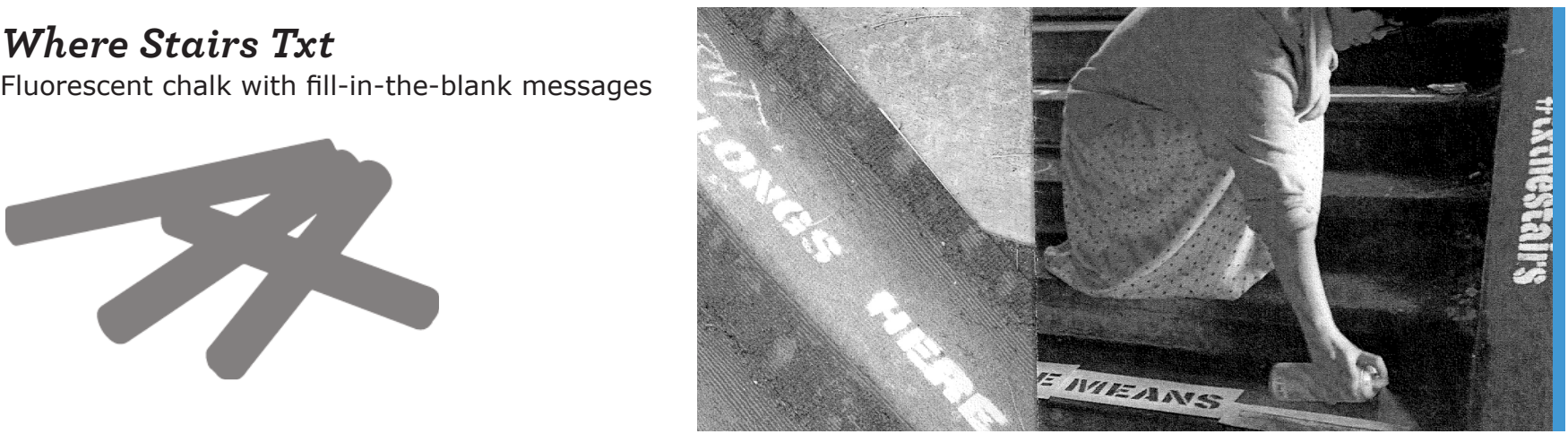


\section{Probe 1 Where Light Belongs}
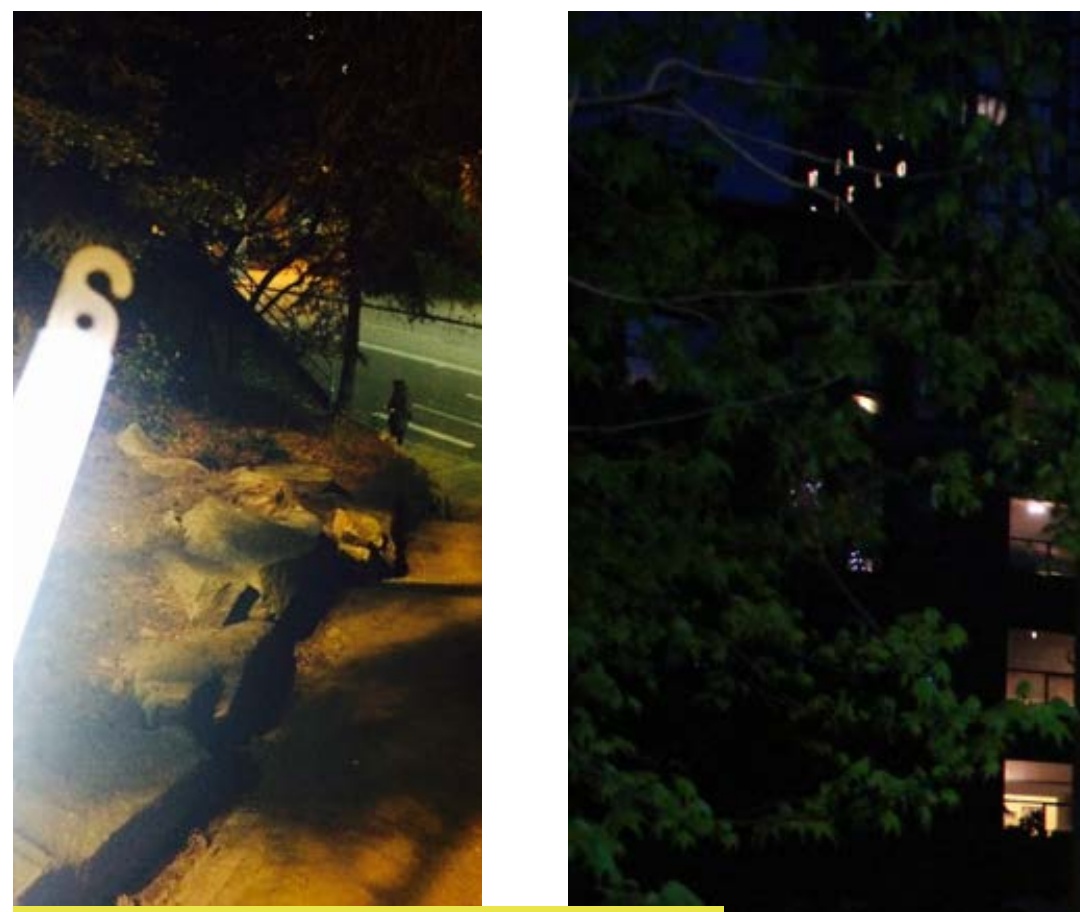

\section{A R K N E S}

Eric carried the light stick up an entire set of stairs, but then continued walking. The researcher walked alongside him, wondering where they were headed. She, matched his pace and fast breathing as he marched ahead. He insisted that the light belonged not on the stairs but in an even darker spot on his commute. Several blocks away, on a truly dark strip, he hung the light from a tree. Eric explained that the trees and absence of street lamps make it very dark there. It is one of many spots around the area that don't feel safe to him. 


\section{Probe 2 Where Messages Flow}

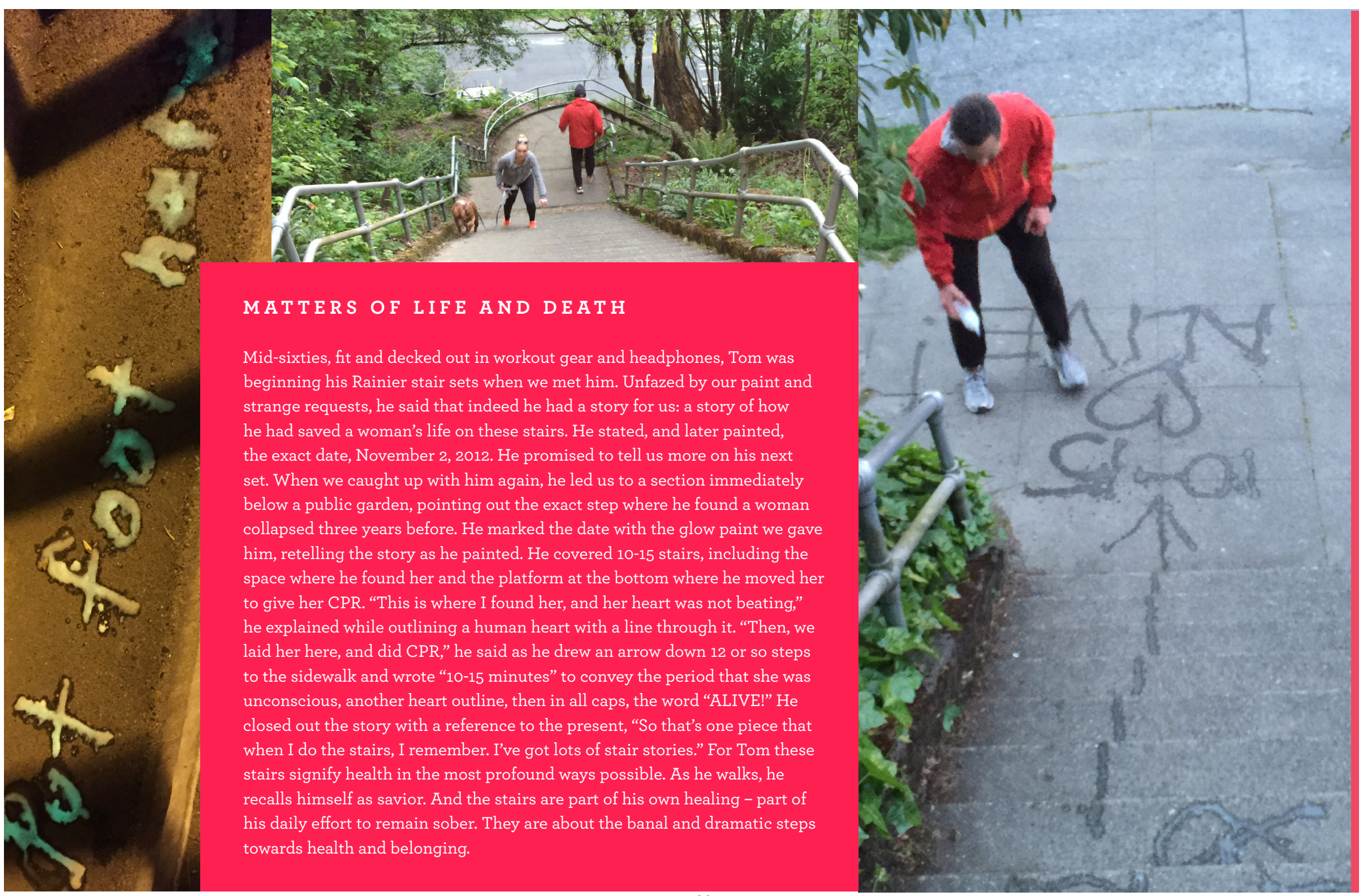




\section{Probe 3 Where Stairs Txt}
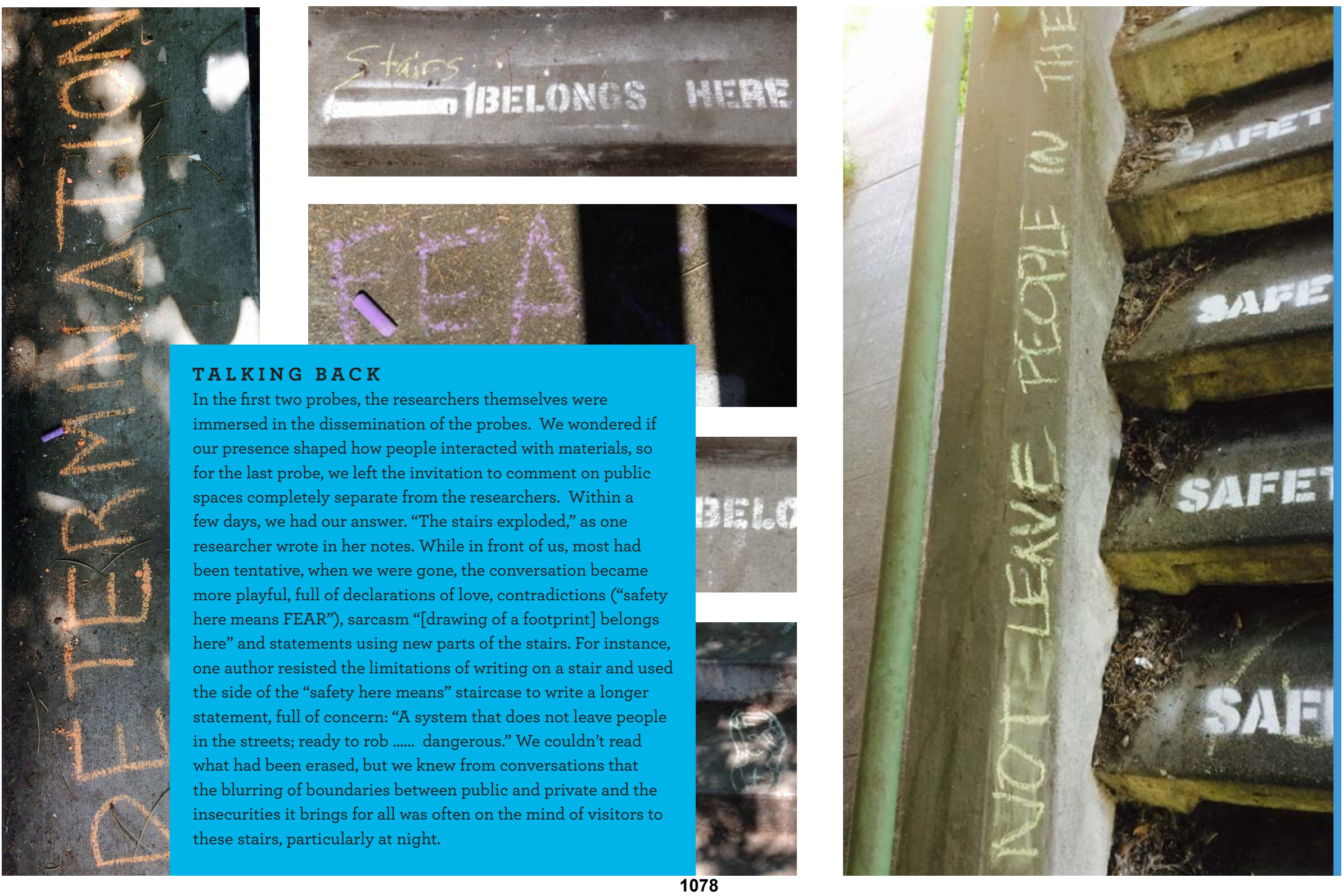


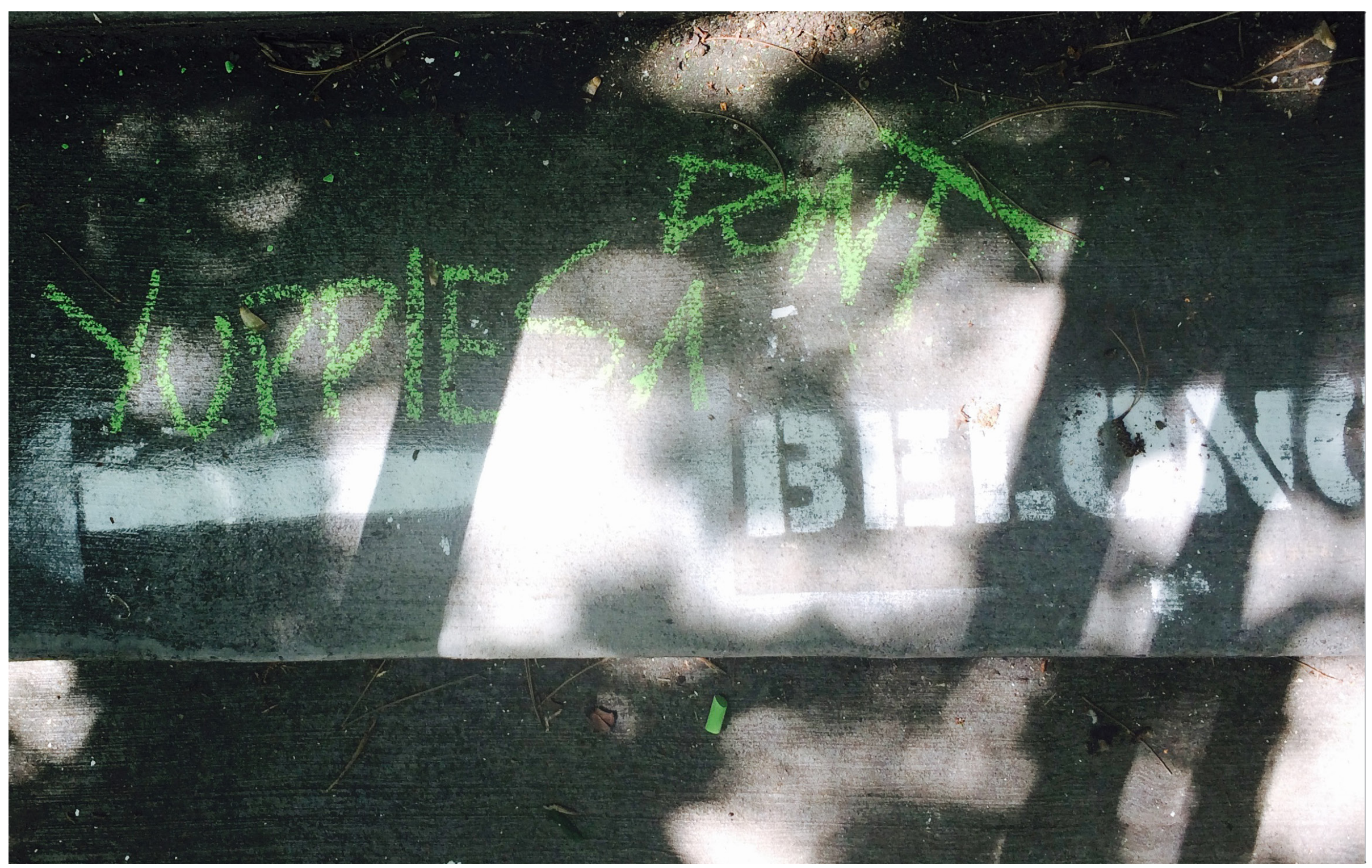




\section{Beyond the Artifacts}

\section{Living Probes}

The conversations triggered by these probes - during and after our interventions - allowed us a persistent engagement with these public sites. Our inquiry thus extended beyond the probes themselves to the people and events that passed through these spaces, or at least until the rain dissolved the messages left. The watery nature of our paint, the dependency on darkness for visible luminescence, or the loose quality of the chalk all reinforced this temporary and changing nature of our inquiry.
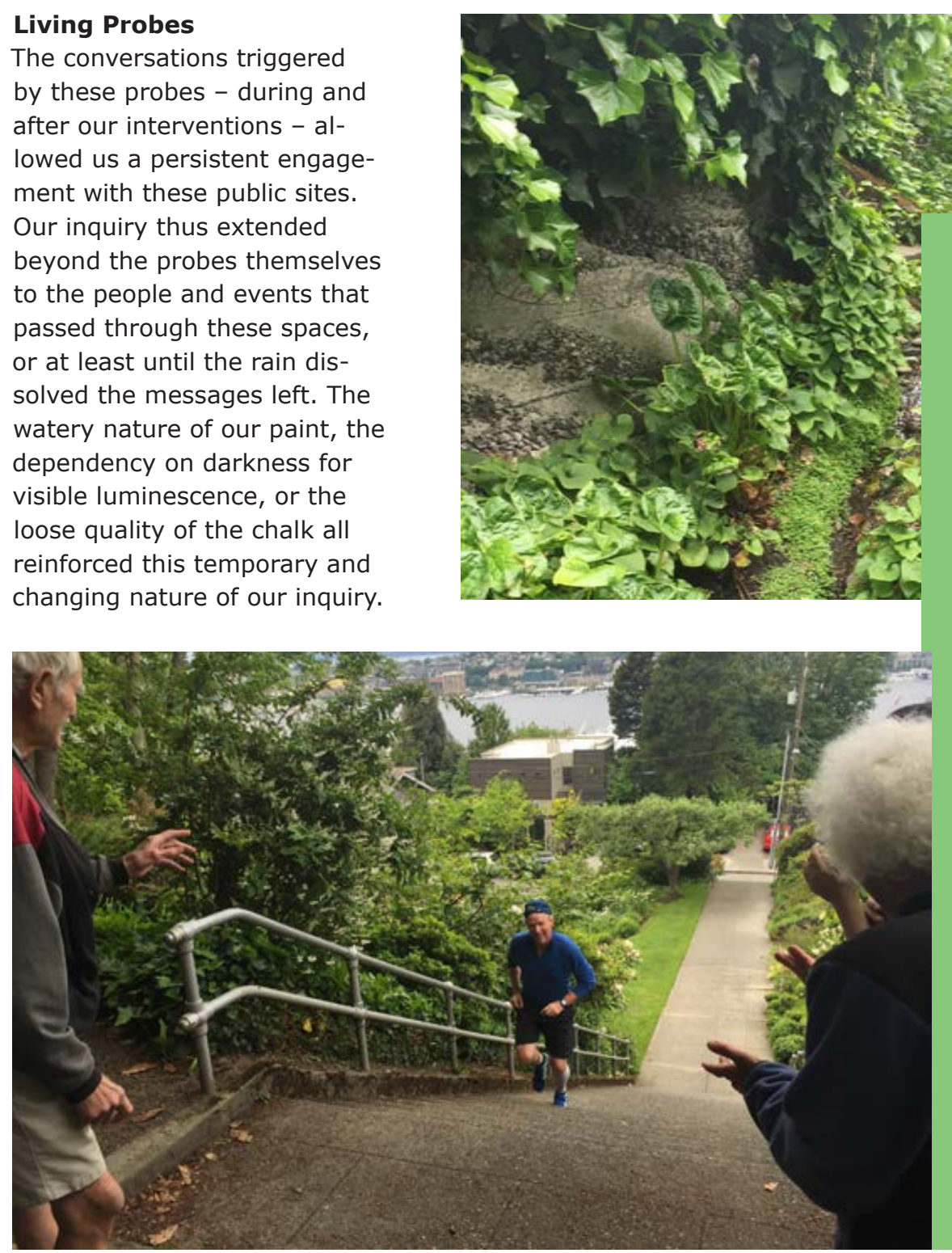
ours. The stair system has built relationships." Ann laughed. "Yes, like ours!"

she exclaimed. "It's been really an important part of our lives, to have responsibility of the stairs."

Today Dan and Ann's collective backyards form a single garden with a spring and a footpath that runs from their property, across the stairs and into a larger plot of public garden. These public gardens started out wild, but Dan and Ann, persistent and patient gardeners, "kept pushing back." Now official with the city, the gardens get cultivated by Dan and Ann "as long as they can."

As we walked through the gardens, Dan pointed to the demarcations of the land we failed to see. He took us to particular plants and explained when they were planted, he led us to the very edge of the park to show us how it looked when they found it: a massive tangle of ivy and plants. The city owned thirty feet on either side of the stairs, while Dan and Ann only own about five feet. But they gardened much more. This was public land, but it was also theirs to care for. Their care extended from the garden to the stairs and the community of people who walked the stairs regularly. 


\section{Conclusions and Future Work}

The temporary interventions we examined in this pictorial were accompanied by fluid methods of inquiry. We approached our itinerant probes as not simply individualized, mediated artifacts, but instead as dynamic events that invite people to re-engage with a particular space. The probes lived within public sites and enlivened a host of personal and collective memories. In emphasizing those intimate histories, our project focused primarily on inquiry rather than design solutions. We surfaced the diverse relationships that play out in public space, from daily exercise rituals associated with one's own recovery to bold acts of altruism. As one person told us, "We have been caring for things that aren't ours for years." Our probes and the encounters they made possible highlighted the intimate nature of collective life.

As ephemeral interventions, itinerant probes illuminated material histories and relationships that came from people's feelings of connection to the space. An example is the merging of Dan and Ann's adjacent backyards and the development of public space that occurred over the course of their courtship. But those spaces still needed cultivation, otherwise they would fall into disrepair. Here itinerant probes use fragility - of the gardens, of the memories rehearsed, and of the social relations enacted - as a starting point for inquiry.

In Gaver's Presence Project, probes came to life as design inspiration: catalyzing conversations with people for whom the designers hoped to build new things. Subsequent research has positioned probes as "mediat[ing] both the relationship between participant and researcher and participant and her own feelings in relation to a question" [7:p.2626]. Our inquiry broadens this work to examine probes as more than mediating objects and more than individual accounts. Here itinerant probes allowed us to study and ignite participatory engagements through artifacts, revealing probes as sites of "material participation" [6]. These sites raised new hopes and implications for belonging, whether responsibilities for upkeep of public space or the healing enacted through its engagement.

Beyond contributing to design probes traditions, treating probes as itinerant artifacts offers new possibilities for studying public encouters. Tom, Dan and Ann's stories show how probes may exceed the engagements of the researcher and the participant, blurring our roles as designers, social researchers, community residents, and activists. For designers, such engagements may help broaden approaches to situated inquiry to involve the material histories of research sites. For social researchers, the probes invite extensions to the interventions they imagine, helping researchers communicate in the field. Together, they highlight multiple ways participation unfolds in public space, pointing to new sites of understanding through material intervention.

As we move forward with this work, we wish to make room for diverse interpretations of collective engagment, both within Seattle and beyond. What new kinds of aspirations and concerns do itinerant probes push us toward? Furthering our explorations of material expression invites new attention to surrounding differences. It demands responding to the varied temporal orders in which our probes are embedded. Some interventions may only appear during rainfall, for example, while others might follow the residues of communal living. In each case, our insights into public life will depend on artfully opening up the participation within.

\section{Acknowledgements}

We would like to thank our talented collaborators Acacio Domar, Allie Deford, and Wanlin Li, our generous reviewers, and the grant support provided by Intel Corporation and NSF \#1523579. 


\section{References}

[1] Boehner, Kirsten, William Gaver, and Andy Boucher. "14 Probes." Inventive Methods: The happening of the social (2012): 185.

[2] Dominguez Rubio, Fernando. "On the discrepancy between objects and things: An ecological approach." Journal of Material Culture (2016).

[3] Gaver, William H., Ben Hooker, Anthony Dunne, and Paul Farrington. "The Presence Project." RCA CRD Projects Series. (2001)

[4] Ingold, Tim. "The textility of making." Cambridge Journal of Economics (2009).

[5] Joyce, R.A. and S.D. Gillespie. "Things in Motion: Object Itineraries in Anthropological Practice" (2015), URL (consulted April 2016): https://sarweb.org/?short_seminar things in motion
[6] Marres, Noortje. Material participation: technology, the environment and everyday publics. Palgrave Macmillan (2012).

[7] Rosner, Daniela K., Miwa Ikemiya, Diana Kim, and Kristin Koch. "Designing with traces." In Proceedings of the SIGCHI Conference on Human Factors in Computing Systems, pp. 1649-1658. ACM (2013).

[8] Wallace, Jayne, Peter C. Wright, John McCarthy, David Philip Green, James Thomas, and Patrick Olivier. "A design-led inquiry into personhood in dementia." In Proceedings of the SIGCHI Conference on Human Factors in Computing Systems, pp. 2617-2626. ACM (2013). 